\title{
Morphology and Mechanical Properties of Poly(ethylene terephthalate)-Poly(hydroxybenzoic acid) and Polycarbonate Blends
}

\author{
Sang Hoon JUNG and Sung Chul KIM* \\ Department of Chemical Engineering, \\ Korea Advanced Institute of Science and Technology, \\ P.O. Box 131, Dongdaemun, Seoul, Korea
}

(Received June 17, 1987)

\begin{abstract}
Blends of an engineering plastic; polycarbonate (PC) and a liquid crystalline polymer; random copolymers of the poly(ethylene terephthalate) and the poly(hydroxybenzoic acid) were prepared in an internal mixer. Fibers were extruded from the capillary rheometer and spin-drawn at varying draw ratios. The morphology and the mechanical properties were investigated by DSC, SEM, polarizing optical microscopy, X-ray diffraction, and tensile tests. SEM studies revealed that the liquid crystalline polymer (LCP) formed finely dispersed spherical domains with a diameter of $0.2-2.0$ micron in the PC matrix and the inclusions were deformed from the spherical droplets to fibrils as the draw ratio increased. The interphase adhesion between the two polymers was good and therefore it was confirmed that the LCP could act as a reinforcement of PC.

KEY WORDS Thermotropic/Liquid Crystalline Polymer / Polycarbonate / Poly(ethylene terephthalate)-Poly(hydroxybenzoic acid) / Liquid Crystalline Polymer Blend / Blend Fiber / Orientation / Interphase Adhesion / Melt Processing /
\end{abstract}

There has been a considerable interest in liquid crystalline polymers (LCP's), especially after the development of high modulus and high strength fibers prepared from the lyotropic aromatic polyamides (aramids) by du Pont. $^{1,2}$ Orientation of chains in the fluid state can be achieved in the melt (thermotropic) or solution (lyotropic) and proper processing can lead to a highly oriented extrudate with exceptional physical properties. Thermotropic liquid crystalline polymers (TLCP's) are currently of considerable interest because of their potential application as ultra-high strength fibers and molded articles. ${ }^{3}$ Unlike lyotropic liquid crystalline polymers (LLCP's), these TLCP's can be easily processed using the conventional extrusion, injection molding and melt spinning equipment. Besides, articles fabricated from TLCP materials have shown mechanical properties generally superior to conventional fiber-reinforced engineering plastics. ${ }^{4}$ Solvent resistance as well as the dimensional stability are also very good.

The blends of LCP's with other engineering plastics to reinforce the mechanical properties were also of interest ${ }^{5-7}$ and the development of advanced polymer composites reinforced by LLCP, such as Kevlar, was reported by Takayanagi et al $^{8-12}$ They observed fine dispersions of $15-30 \mathrm{~nm}$ diameter microfibrils of poly ( $p$-phenylene terephthalamide) in a matrix of nylon 6 or nylon 66 in the so-called "molecular composite." 8 The ease of melt processing combined with the high performance

\footnotetext{
* To whom correspondence should be addressed
} 
characteristics makes the thermoplastic LCP blend with engineering plastics very attractive. $^{5-7,13}$

The purpose of this study is to investigate the morphological change during orientation and the mechanical properties of the TLCP blends with polycarbonate (PC) in the molten state. At the processing temperature, the melt viscosity of the TLCP blend is expected to be significantly lower than that of the conventional reinforcement compositions, i.e., using glass fiber or carbon fiber. By using TLCP melt as a reinforcement, the preferential orientation of liquid crystalline component is anticipated to give an anisotropic fibrous reinforcing phase. Such a fiber-like liquid crystalline phase will lead to an increase in the mechanical properties equivalent to those attained by conventional fiber reinforced resins.

\section{EXPERIMENTAL}

\section{Materials and Preparation of the Blend Fiber}

The liquid crystalline polyester used as a reinforcing polymer in this study was provided by Tennessee Eastman Kodak Co. and composed of the copolymer of $40 \mathrm{~mol} \%$ poly(ethylene terephthalate) (PET) and $60 \mathrm{~mol} \%$ p-hydroxybenzoic acid (PHB) (X7G, i.v. = 0.77). ${ }^{14,15}$ The matrix resin was polycarbonate (PC) manufactured by the General Electric Co. under the trade name of Lexan. The blending of the two polymers was carried out in the molten state under nitrogen atmosphere. The two resins, dried in a vacuum oven at $110^{\circ} \mathrm{C}$ for 8 hours, were mixed in an internal mixer (Rheomix 600, Haake Inc.). In order to achieve better dispersion, two polymers were loaded sequentially. PC was first loaded at $250^{\circ} \mathrm{C}$ and mixed for two minutes in the rotating mixer, and PET-PHB was charged subsequently and mixed for two minutes. Finally the temperature was raised to $260^{\circ} \mathrm{C}$ at a rate of $5^{\circ} \mathrm{C} \mathrm{min}^{-1}$ and held for two minutes at that temperature. The rotor speed was fixed at $30 \mathrm{rpm}$. The blends were extruded from a capillary rheometer (Instron 3211) using a capillary of $5.0851 \mathrm{~cm}$ in length and $\mathrm{L} / \mathrm{D}$ ratio of 40 . The extrusion temperature was $265^{\circ} \mathrm{C}$ which was above the PHB crystal melting point. ${ }^{13,16}$ To avoid contact with moisture, a continuous stream of dry nitrogen was introduced over the upper part of the barrel during the extrusion. The apparent shear rate was $116.7 \mathrm{~s}^{-1}$. In order to investigate the effect of orientation on morphology, the extrudates were elongated by a take-up machine located $10 \mathrm{~cm}$ below the capillary and all the elongated fibers were quenched immediately in water. The spin draw ratio (D.R.) was determined by measuring the decrease in diameter of the fibers.

\section{Measurements}

Differential Scanning Calorimetry (DSC). Thermal analyses of the blends were performed by a du Pont 910 Thermal Analyzer. All the runs were under nitrogen atmosphere with a heating or cooling rate of $10^{\circ} \mathrm{C} \mathrm{min}^{-1}$. The DSC curves obtained from the second run was taken for the analysis.

Polarized Light Microscopy. The optical texture of the blends were observed between glass slides with an American Optics Microscope on a hot stage in the temperature range from $30^{\circ} \mathrm{C}$ to $450^{\circ} \mathrm{C}$.

Scanning Electron Microscopy (SEM). SEM (JEOL JSM-35CF) was used to analyze the morphology of the blend fibers. The fibers were embedded in epoxy resin and fractured at cryogenic temperature. Fractured surfaces were coated with gold for the microscopy.

Tensile Measurements. Tensile properties were investigated by using an Instron Model 4201 tensile tester with a gauge length of $40 \mathrm{~mm}$ and a strain rate of $5 \mathrm{~mm} / \mathrm{min}$ at room temperature. Average values of ten measurements were taken.

$X$-Ray Data. Wide-angle X-ray diffraction patterns were obtained from the blend fiber bundles with a Rigaku Geigerflex X-ray diffractometer having a $\mathrm{Ni}$-filtered $\mathrm{Cu}-K_{\alpha}$ ra- 
diation $(37.5 \mathrm{kV}, 17.5 \mathrm{~mA})$ and a flat-plate camera. The distance from the sample to the film was $35 \mathrm{~mm}$ and the exposure time was about $60 \mathrm{~min}$. An orientation angle for each fiber was obtained from angular scans through a principal equatorial reflection. The orientation angle was taken to be the half-width of the angular scan.

\section{RESULTS AND DISCUSSION}

\section{Thermal Behavior}

The thermal properties of the blends were investigated by differential scanning calorimetry (DSC). The liquid crystalline polyester had a glass transition temperature, $T_{\mathrm{g}}$, at $56^{\circ} \mathrm{C}$ and the $T_{\mathrm{g}}$ remained constant when blended with polycarbonate (Figure 1). The polycarbonate $T_{\mathrm{g}}$ at $149^{\circ} \mathrm{C}$ decreased as the polyester content was increased due to the partial mixing of LCP with PC. Such a depression was also confirmed by the dynamic mechanical analysis (not shown in this paper). A weak endothermic and an exothermic peak associated with the melting and crystallization of LCP, respectively, were observed (Figure 2). The endothermic peak corresponding to the crystal melting of PET segment in $\mathrm{LCP}^{13,16}$ occurred at the same temperature but the onset of crystallization and the crystallization peak temperature of the PET segment shifted towards lower temperature as the PC content increased. It is suggested that PC has an unfavorable effect on the crystallization of LCP in the blend. The transition temperatures are listed in Table I.

\section{Morphology}

The morphology of the blend was investigated by the scanning electron microscopy (SEM) of the fractured surface prepared in liquid nitrogen. Figure 3 shows the fractured surface of the blends extruded by the capillary rheometer at draw ratio of 1 . In Figure $3 a$, the extrudates of $100 \% \mathrm{LCP}$ are seen to be fibrillar in character but the degree of fibrillation is low

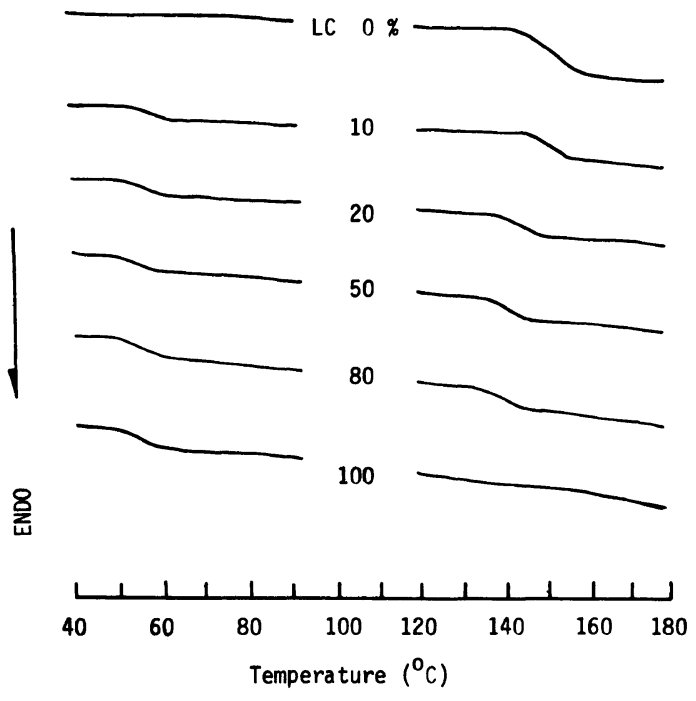

Figure 1. Glass transition temperature of $\mathrm{LCP} / \mathrm{PC}$ blends.
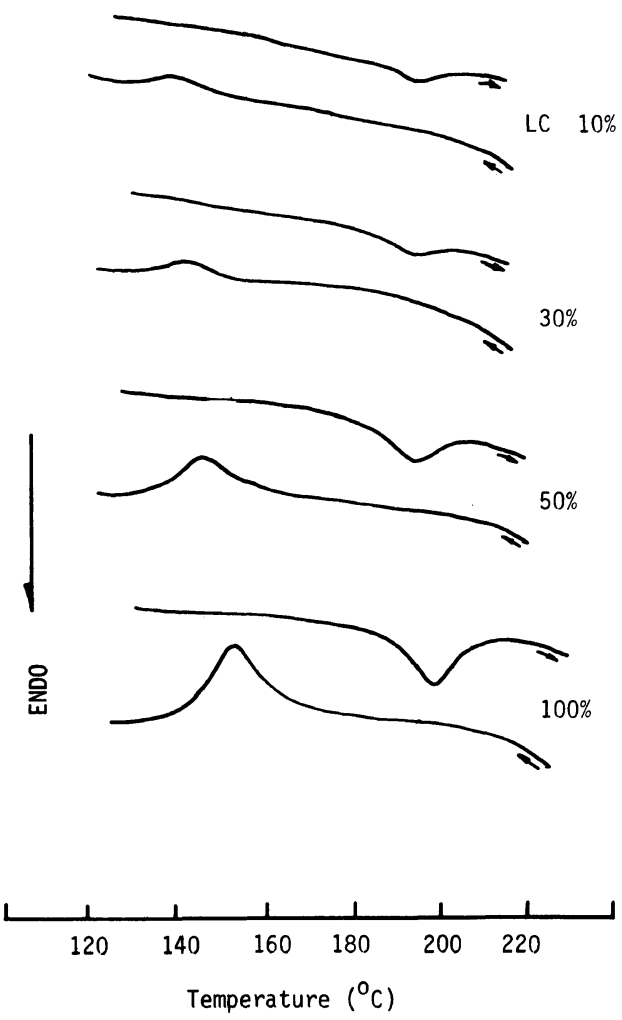

Figure 2. DSC curves of crystallization and melting of $\mathrm{LCP} / \mathrm{PC}$ blends (scan rate, $10^{\circ} \mathrm{C} \mathrm{min}^{-1}$ ). 


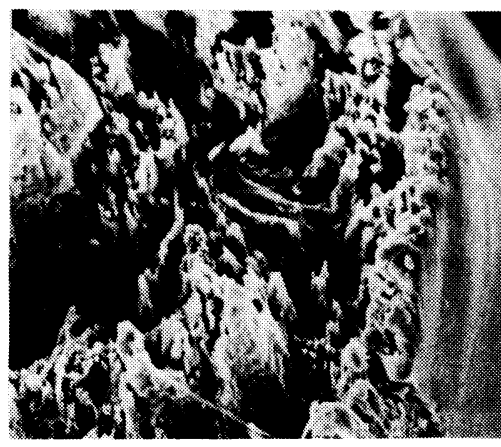

(a)

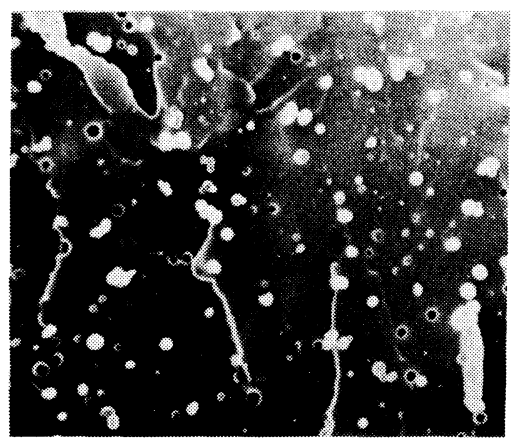

(c)

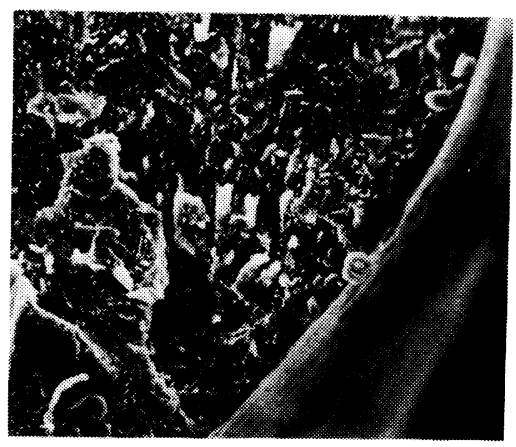

(b)

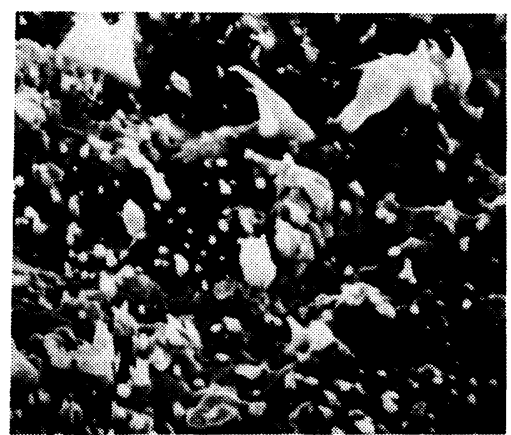

$3 \mu \mathrm{m}$

Figure 3. Scanning electron micrographs of the fractured surface of LCP/PC blends (D.R. $=1$ ).

(a) 100/ 0; (b), (c) 10/90; (d) 30/70.

Table I. Thermal transition of LCP/PC blends

\begin{tabular}{|c|c|c|c|c|}
\hline LC content & $T_{\mathrm{g} 1}^{\mathrm{a}}$ & $T_{\mathrm{g} 2}^{\mathrm{b}}$ & $T_{\mathrm{m}}^{\mathrm{c}}$ & $T_{\mathrm{c}}^{\mathrm{d}}$ \\
\hline$\%$ & ${ }^{\circ} \mathrm{C}$ & ${ }^{\circ} \mathrm{C}$ & ${ }^{\circ} \mathrm{C}$ & ${ }^{\circ} \mathrm{C}$ \\
\hline 0 & - & 149 & - & - \\
\hline 3 & - & 148 & - & - \\
\hline 5 & - & 147 & - & - \\
\hline 10 & 58 & 146 & 197 & 140 \\
\hline 20 & 57 & 143 & 197 & 140 \\
\hline 30 & 57 & 142 & 197 & 141 \\
\hline 50 & 57 & 139 & 197 & 144 \\
\hline 80 & 56 & 139 & 197 & 147 \\
\hline 100 & 56 & - & 198 & 152 \\
\hline
\end{tabular}

a Glass transition temperature of LCP in the blends.

b Glass transition temperature of $\mathrm{PC}$ in the blends.

c Melting temperature of LCP.

d Crystallization peak temperature of LCP. due to the semi-rigid nature of the LCP. ${ }^{3}$ The surfaces of LCP/PC (10:90) blend are shown in Figures $3 b$, c. The spherical LCP particles are finely dispersed with a diameter of $0.2-0.5 \mu \mathrm{m}$ in a PC matrix. However, as the LCP content was increased to $30 \mathrm{wt} \%$, the size of inclusion increased to $0.3-2.0 \mu \mathrm{m}$ owing to the agglomeration of the droplet in the molten state. The blend with $10 \%$ LCP extruded at draw ratio of 1 was slightly deformed as shown in Figure $4 \mathrm{a}$ where we could see dumbbell-like LCP inclusions. The effect of spin-drawing on the orientation of LCP particles in the PC matrix is shown in Figure $4 b$. In Figure $4 b$, the fractured surface of the oriented fiber revealed that the LCP particles embedded in PC matrix were elongated to rod-like fibrils. The fibrillar structure of the blends extruded and 


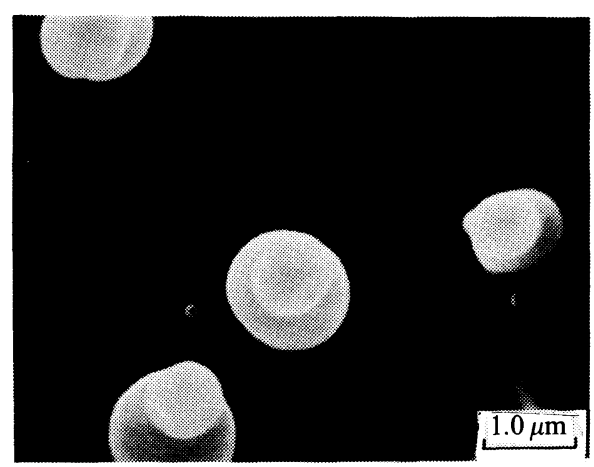

(a)

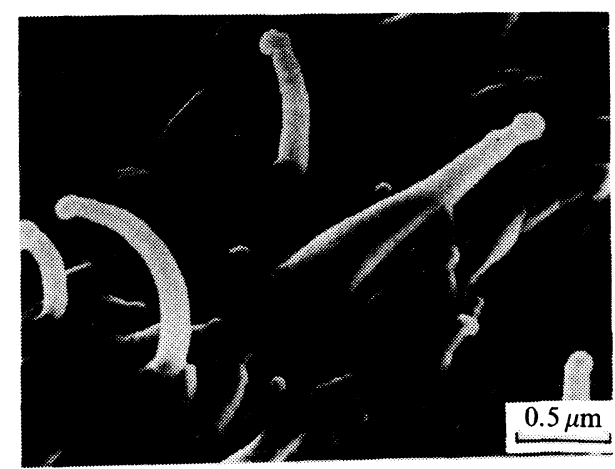

(b)

Figure 4. Scanning electron micrographs of LCP/PC (10/90) blend. (a) D.R. =1; (b) D.R. $=15$.

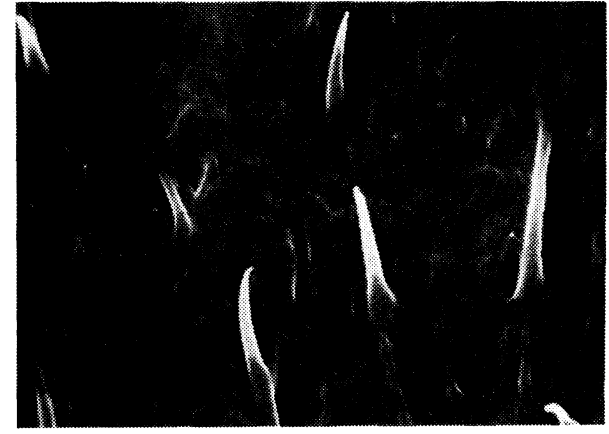

(a)

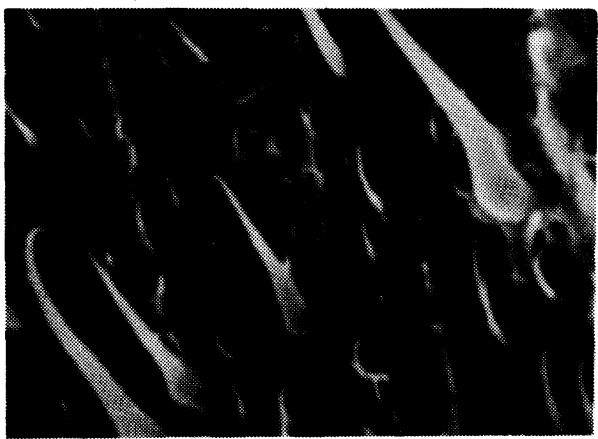

(c)

drawn indicated that the interphase adhesion between the two polymers was quite good and no particle pullout took place during the drawing process. It is expected that the reinforcement of the mechanical properties with

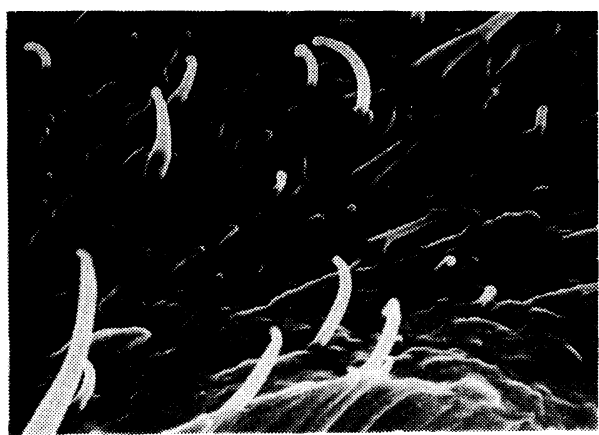

(b)
Figure 5. Scanning electron micrographs of LCP/PC blends (D.R.=15). (a) 5/95; (b) 10/90; (c) 30/70.

the fibrillar LCP domain is significant in the blends. The fractured surfaces of LCP/PC blends of different compositions at draw ratio of 15 show a similar fibrillar orientation of LCP domains (Figure 5). 


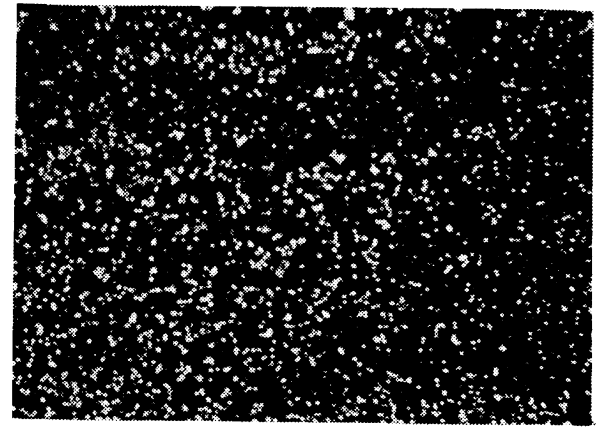

(a)

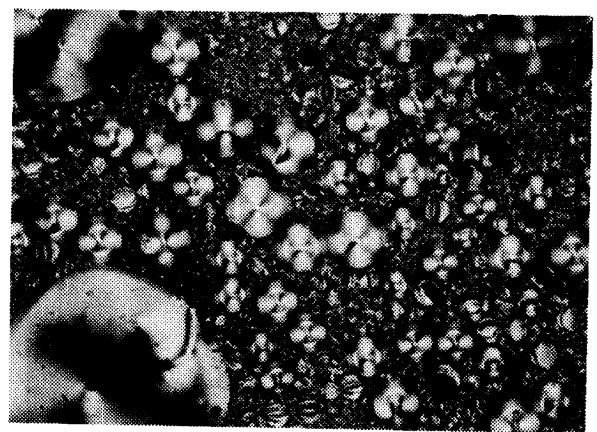

(c)

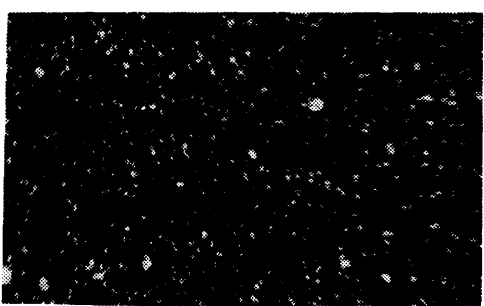

(a)

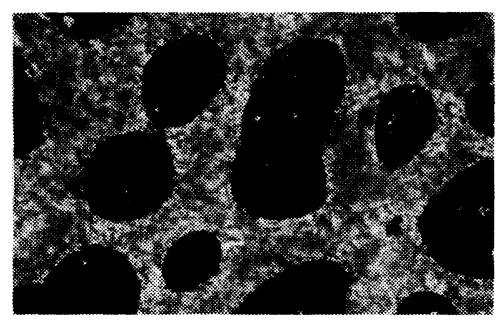

(c)

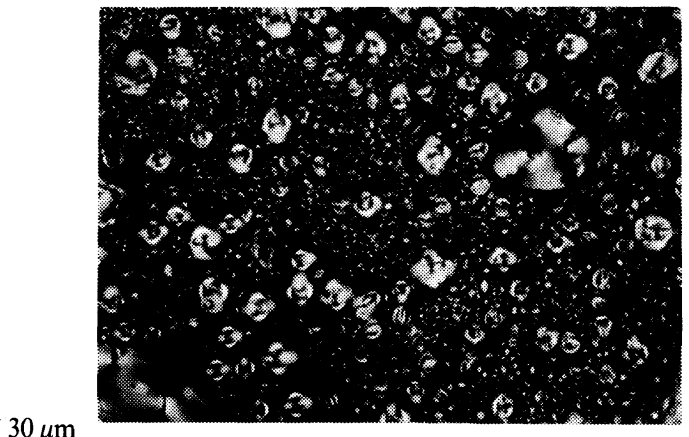

(b)

Figure 6. Textures of a nematic PET-PHB (40:60) copolymer (cooling at $10^{\circ} \mathrm{C} \mathrm{min}^{-1}$ after holding at $400^{\circ} \mathrm{C}$ for $30 \mathrm{~min}$ ). (a) at $390^{\circ} \mathrm{C}$; (b) at $300^{\circ} \mathrm{C}$; (c) at $275^{\circ} \mathrm{C}$.

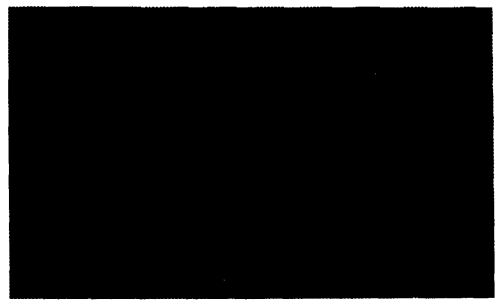

(b)

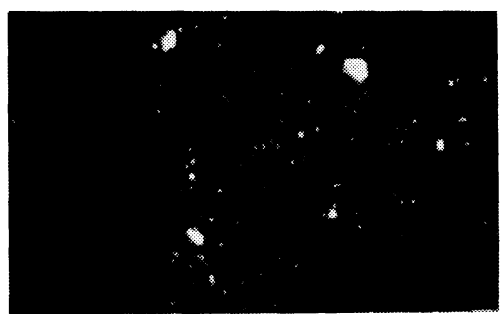

(d)

Figure 7. Polarized optical micrographs showing the disappearance of the LCP domains due to the transesterification between PC and PET-PHB copolymer at $300^{\circ} \mathrm{C}$. (a) LCP/PC (10:90), 0 min; (b) LCP/ PC (10:90), $30 \mathrm{~min}$; (c) LCP/PC (50: 50), $0 \mathrm{~min}$; (d) LCP/PC (50:50), $30 \mathrm{~min}$. 


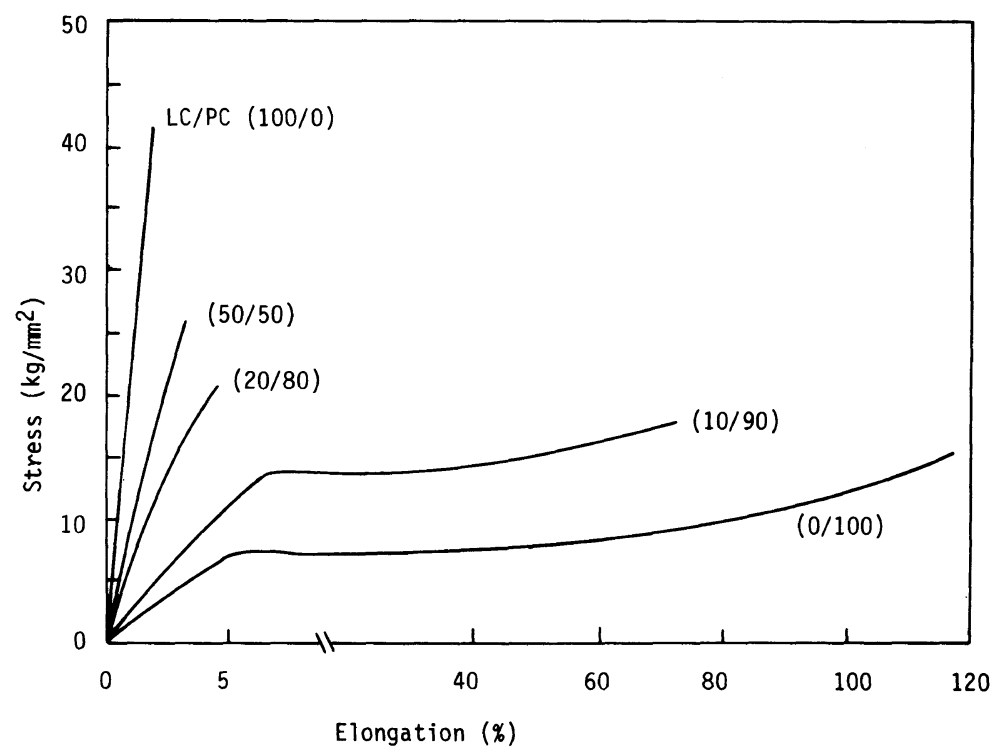

Figure 8. Stress-strain curves for the blend fibers (D.R. $=15)$.

The optical characteristics of the blend was studied with a polarizing microscope equipped with a hot stage. Optical micrographs obtained at different temperatures during the cooling experiment are shown in Figures 6 and 7. It is well known that the PET $-60 \mathrm{~mol} \% \mathrm{PHB}$ copolymer comes to exhibit a mesophase texture at $190^{\circ} \mathrm{C}$ and becomes isotropic fluid at $420^{\circ} \mathrm{C}^{17}$ In our experiment, the polymer exhibited a nematic mesophase at $275^{\circ} \mathrm{C}$ and became totally isotropic at $400^{\circ} \mathrm{C}$ with significant degradation. Figure $6 a$ demonstrates the $a b-$ rupt formation of liquid crystalline texture at $390^{\circ} \mathrm{C}$ when cooled at $10^{\circ} \mathrm{C} \mathrm{min}^{-1}$ after holding the $100 \% \mathrm{LCP}$ at $400^{\circ} \mathrm{C}$ for $30 \mathrm{~min}$. The black areas show the isotropic state of the LCP and white specks reveal the nematic texture. The nematic texture appeared clearly with a size of tens of microns when cooled down to $275^{\circ} \mathrm{C}$. But the optical texture of the blend, on the other hand, reveals a two phase structure of the liquid crystalline phase and the polycarbonate isotropic melt phase. As the LCP content is increased, the agglomeration of LCP occurs as shown in Figure 7c which is in good agreement with the SEM observations of the
Table II. Tensile properties of blend fibers (D.R. $=15)$

\begin{tabular}{|c|c|c|c|}
\hline LCP content & Strength & Elongation & Modulus \\
\hline$\%$ & $\mathrm{~kg} \mathrm{~mm}^{-2}$ & $\%$ & $\mathrm{~kg} \mathrm{~mm}^{-2}$ \\
\hline 0 & 15.1 & 115.5 & 277.1 \\
\hline 3 & 15.4 & 113.7 & 288.4 \\
\hline 5 & 16.7 & 105.2 & 359.4 \\
\hline 10 & 18.7 & 71.9 & 392.6 \\
\hline 20 & 20.2 & 4.3 & 605.8 \\
\hline 30 & 22.6 & 3.2 & 768.3 \\
\hline 50 & 25.1 & 2.7 & 1090.1 \\
\hline 80 & 33.2 & 2.2 & 1780.2 \\
\hline 100 & 41.3 & 1.8 & 2324.7 \\
\hline
\end{tabular}

fractured surface. However, as time elapses at $300^{\circ} \mathrm{C}$, the blend loses its anisotropic texture and becomes isotropic (Figures $7 \mathrm{~b}$ and $\mathrm{d}$ ). A possible explanation of this phenomena is due to the interfacial transesterification reaction $^{15,18}$ and thermal degradation of the liquid crystalline polymer.

\section{Mechanical Properties}

The stress-strain curves for the blend fibers are shown in Figure 8. The blends with over $20 \%$ of LCP exhibit no signs of yielding, and 
the addition of a rigid chain polymer improved the ultimate strength and modulus. Table II lists the average of ten values taken from the stress-strain curves of the blends at draw ratio of 15. Both the ultimate tensile strength and the tensile modulus increased with the introduction of PET-PHB, whereas the elongation at break decreased sharply. The highest modulus obtained in $100 \%$ LCP fiber was $2324.7 \mathrm{~kg} \mathrm{~mm}^{-2}$ (equivalent to about $185 \mathrm{~g} /$ denier). Figures 9 and 10 show the effect of draw ratio (DR) on the ultimate tensile strength and modulus of the blends. Both

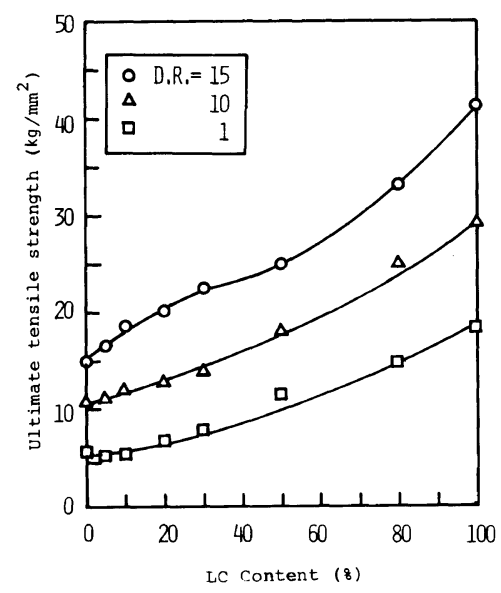

Figure 9. Effect of draw ratio on the tensile strength of LCP/PC blends. show a linear increase in the modulus and in the strength at higher draw ratio as the LCP phases are transformed from droplets to continuous fibers in the blends.

The wide angle X-ray diffraction (WAXD) patterns of the oriented fibers at draw ratio of 10 with increasing LCP content are shown in Figure 11. The scattering patterns of blends with LCP content of $50 \%$ or less appeared mostly diffuse in the blend fibers, and this is due to the amorphous PC matrix. However, the pure LCP fiber shows a high degree of anisotropy in the polymer crystallites. The

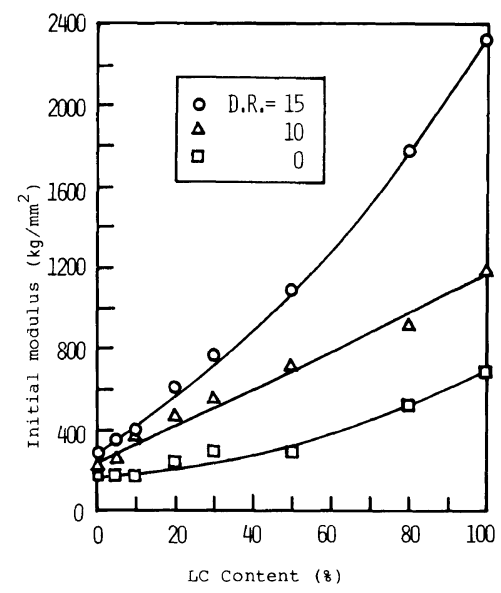

Figure 10. Effect of draw ratio on the initial modulus of LCP/PC blends.

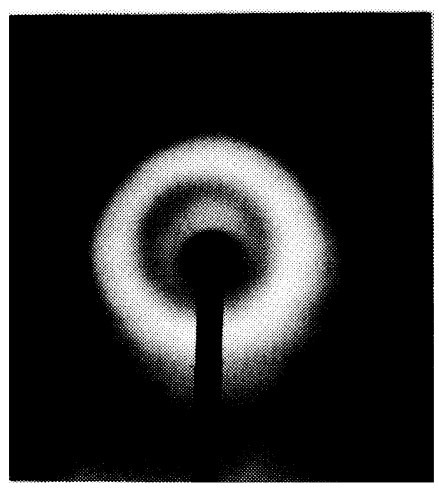

(a)

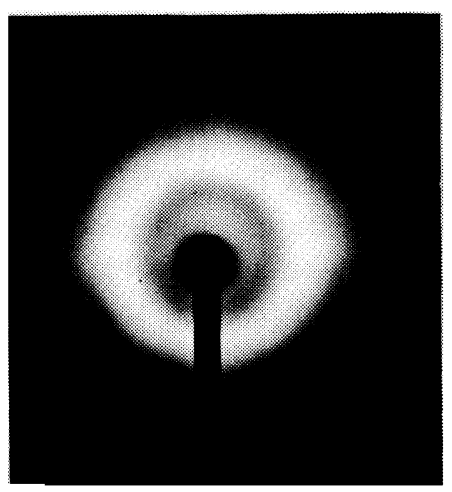

(b)

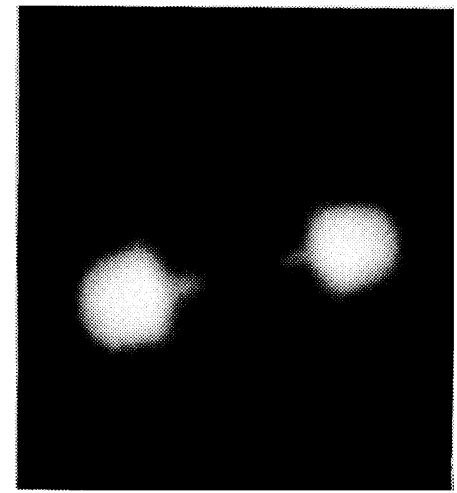

(c)

Figure 11. Wide angle X-ray diffraction patterns of blend fibers. (a) LCP/PC (10:90); (b) LCP/PC (50:50); (c) LCP/PC (100:0). 


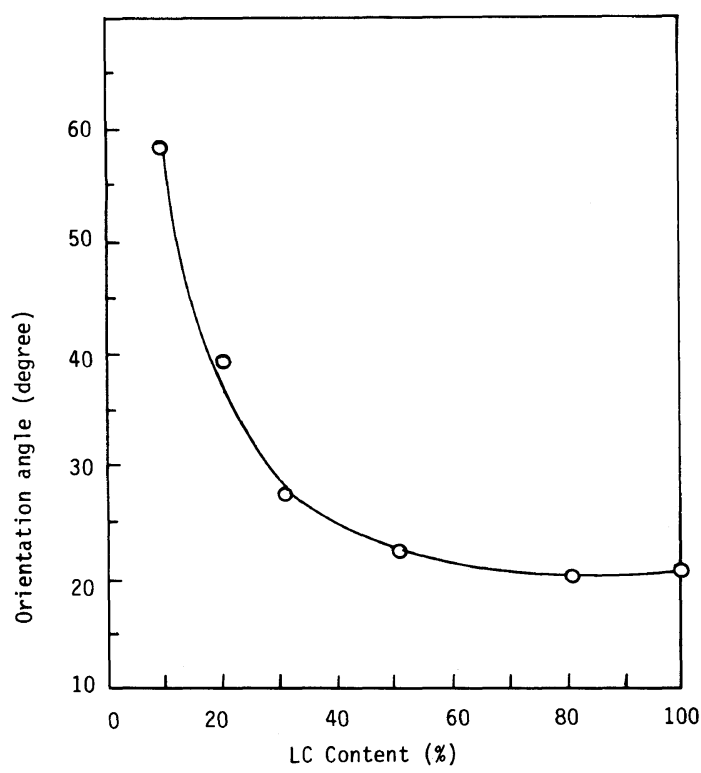

Figure 12. Orientation angle of blend fibers (D.R. = 10).

orientation angles of the blend fiber decreased sharply as the amount of LCP was increased [from $58^{\circ}$ in $\mathrm{LCP} / \mathrm{PC}(10: 90)$ blend to $21^{\circ}$ in pure LCP fiber as shown in Figure 12]. It also shows that the enhancement of mechanical properties with the increasing LCP content is due to the high orientation induced in the LCP/P.C blends.

Acknowledgements. We are pleased to acknowledge the financial support of this work by the SKC Limited (formerly Sunkyong Chemical Limited). We also wish to express our appreciation to Tennessee Eastman Kodak for supplying the LCP polymers.

\section{REFERENCES}

1. S. L. Kwolek, U. S. Patent, 3,671,542 (1972).

2. P. W. Morgan, Macromolecules, 10, 1381 (1977).

3. G. W. Calundann and M. Jaffe, "Anisotropic Polymers, Their Synthesis and Properties," Proceedings of the Robert A. Welch Conferences on Chemical Research, XXVI. Synthetic Polymers, Nov. 15-17, Houston, Texas (1982).

4. Y. Ide and Z. Ophir, Polym. Eng. Sci., 23, 261 (1983).

5. A. Siegman, A. Dagan, and S. Kenig, Polymer, 26, 1325 (1985).

6. F. N. Cogswell, B. P. Griffin, and J. B. Rose, U. S. Patent, 4,386,174 (1983).

7. M. Kimura and R. S. Porter, J. Polym. Sci., Polym. Phys. Ed., 22, 1697 (1984).

8. M. Takayanagi, T. Ogata, M. Morikawa, and T. Kai, J. Macromol. Sci.-Phys., B(17), 591 (1980).

9. M. Takayanagi, Pure Appl. Polym. Sci., 55, 81 (1983).

10. M. Takayanagi and K. Goto, J. Appl. Polym. Sci., 29, 2547 (1984).

11. K. Yamada, M. Uchida, and M. Takayanagi, $J$. Appl. Polym, Sci., 32, 5231 (1986).

12. W. F. Hwang, D. R. Wiff, C. L. Benner, and T. E. Helminiak, J. Macromol. Sci.-Phys., B(22), 231 (1983).

13. E. G. Joseph, Ph D. Dissertation, Virginia Polytechnic Institute and State University (1983).

14. H. F. Kuhfuss and W. J. Jackson, Jr., U.S. Patent, 3,778,410 (1973).

15. W. J. Jackson, Jr. and H. F. Kuhfuss, J. Polym. Sci., Polym. Chem. Ed., 14, 2043 (1976).

16. E. G. Joseph, G. L. Wilkes, and D. G. Baird, Polymer, 26, 689 (1985).

17. C. Viney and A. H. Windle, J. Mater. Sci., 17, 2661 (1982).

18. F. L. Hamb, J. Polym. Sci., A-2, 10, 3217 (1972). 